\title{
Between the blabbering noise of individuals or the silent dialogue of many: A collective response to 'Postdigital Science and Education' (Jandrić et al. 2018)
}

Sonja Arndt (University of Waikato, New Zealand, sonja.arndt@waikato.ac.nz), Gordon Asher (Independent Scholar, Scotland, gordonasher@hotmail.com), Jeremy Knox (University of

Edinburgh, UK, jeremy.knox@ed.ac.uk), Derek R. Ford (DePauw University, US, derekford@depauw.edu), Sarah Hayes (University of Wolverhampton, UK,

Sarah.Hayes@ wlv.ac.uk), George Lăzăroiu (The Cognitive Labor Institute, US, lazaroiu@aaer.org), Liz Jackson (University of Hong Kong, China, lizjackson@ @ku.hk), Julia Mañero Contreras (University of Seville, Spain, julmancon@gmail.com), Rachel Buchanan (University of Newcastle, Australia, Rachel.Buchanan@ @ewcastle.edu.au), Laura D’Olimpio (University of Birmingham, UK, L.DOlimpio@bham.ac.uk), Mark Smith (Loughborough University, UK, M.Smith2@ lboro.ac.uk), Juha Suoranta (Tampere University, Finland, juha.suoranta@gmail.com), Olli Pyyhtinen (Tampere University, Finland, Olli.Pyyhtinen@uta.fi), Thomas Ryberg (University of Aalborg, Denmark, ryberg@hum.aau.dk), Jacob Davidsen (University of Aalborg, Denmark, jdavidsen@ @um.aau.dk),

Anne Steketee (Chapman University, US, steke101@mail.chapman.edu), Ramona Mihăilă (Dimitrie Cantemir Christian University, Romania, ramona.mihaila@gmail.com), Georgina Stewart (Auckland University of Technology, New Zealand, georgina.stewart@aut.ac.nz), Mark Dawson (Lancaster University, UK, mark.dawson@lancaster.ac.uk), Christine Sinclair (University of Edinburgh, UK, Christine.Sinclair@ed.ac.uk), Michael A. Peters (Beijing Normal University, China, mpeters@bnu.edu.cn)

\begin{abstract}
This article is a multi-authored response to an editorial 'Postdigital Science and Education' published in 2018 by Petar Jandrić, Jeremy Knox, Tina Besley, Thomas Ryberg, Juha Suoranta, and Sarah Hayes in Educational Philosophy and Theory as a mission statement for the journal Postdigital Science and Education. Nineteen authors were invited to produce their sections, followed by two author-reviewers who examined the article as a whole. Authors' responses signal the sense of urgency for developing the concept of the postdigital and caution about attempts at simplifying complex relationships between human beings and technology. While the digital indeed seems to become invisible, we simultaneously need to beware of its apparent absence and to avoid over-emphasizing its effects. In this attempt, authors offer a wide range of signposts for future research such as 'the critical postdigital', 'postdigital reflexivity', and others; they also warn about the group's own shortcomings such as the lack of 'real' sense of collectivity. They emphasize that postdigital education must remain a common good, discuss its various negative aspects such as smartphone addiction and nomophobia, and exhibit some positive examples of postdigital educational praxis. They discuss various aspects of postdigital identities and point towards the need for a postdigital identity theory. With these varied and nuanced responses, the article opens a wide spectrum of opportunity for development of postdigital approaches to science and education for the future.
\end{abstract}

Keywords: postdigital, dialogue, collective, science, education, identity

\section{Introduction (Sonja)}

Navigating 'between the continuous nature of biological existence, and the discrete ('on/off') nature of digital technology' (Jandrić, Knox et al. 2018: 893), the postdigital ruptures conceptions of certainty and knowledge in education. By unsettling conventional and long-established constructions 
of ourselves in our human engagement with, by, even as, technology, the postdigital shakes educational orientations and ideals at their very (humanist, knowable) roots. This paper tackles the postdigital educational realm in a collection of responses to an editorial titled 'Postdigital Science and Education' published by Petar Jandrić, Jeremy Knox, Tina Besley, Thomas Ryberg, Juha Suoranta, and Sarah Hayes in Educational Philosophy and Theory as a mission statement for the journal Postdigital Science and Education (Jandrić, Knox et al. 2018). The authors of the editorial raise questions in relation to the realities evoked in the postdigital temporal and educational milieu, sparking the responses and reactions below.

This collection of responses emphasizes the significance of the topic, for example asking whether talking about the postdigital means that the digital revolution is over now? Or, alternatively, whether it means that we remain embedded in its depths to such an extent that it has already immersed us in some kind of new normal (and if so, what is that normal?)? Has technology and all that we call 'digital' become so entrenched, in our banal everydayness, that we no longer even notice it? Are we experiencing this new normal in ways which were never imagined, which lead us constantly into the new, the feared, the dangerous - or conversely into a realm of delight, discovery, adventure or freedom?

As a confluence of views on the postdigital, this collective piece is a provocation. It provokes ongoing dialogue amongst ourselves and other authors, thinkers, workers, students, children - citizens in the digital realm. It plays out not only in the Western world, but provokes a blurring of binaries dependent on classification systems such as Western and non-Western, poverty indicators, educational benchmarks, class, race, ethnicity, and others that too frequently result in educational segregations and marginalisations. This paper plays out the idea of dialogue as an encounter, not only with the words of the writers, those uttered in the sections that follow, but rather, each piece in this collective paper draws also on past views by which the authors have been affected, each author's present experiences, and their hopes, dreams, aspirations, their hidden or not so hidden worries about the future. The complex nature of dialogue means that it can act as both a bridge and a fissure, and this task should not be taken lightly. While the authors of this paper are connected in that their responses all depart from the editorial by Jandrić and his colleagues, they are nevertheless also individual. What the authors share reveals both agreements and tensions, philosophical orientations, and personal and institutional views, arising from each of their diverse origins. They explicate the complexity of both postdigital futures and collective and individual academic subjectivities (Peters, Besley, and Arndt 2019). Finally, this paper is intended as an ongoing provocation: towards and for developing postdigital dialogues, pedagogies and futures, and the collective potential of our own and future author/s' contributions.

\section{Postdigital Science}

What does/might the 'post' in the postdigital suggest: education, eco-social justice, and the critical postdigital? (Gordon)

'the prefix post(-) triggers us to recognise that there is something to talk about in the term that follows' (Sinclair and Hayes 2018: 12) 
'The postdigital is hard to define; messy; unpredictable; digital and analog; technological and non-technological; biological and informational. The postdigital is both a rupture in our existing theories and their continuation' (Jandrić, Knox et al. 2018: 895)

'A technology always has a history, and it has a politics. A technology likely has a pedagogical bent as well' (Morris and Stommel 2018a: xii)

The prefix 'post' has (at least) three, potentially related, meanings (Sinclair and Hayes 2018), namely; after, with, and against. It seems that, for many, such as editors/writers with the new journal Postdigital Science and Education, their understanding and application of the term 'postdigital' incorporates aspects of all three - while often foregrounding a critical conception and approach ${ }^{1}$. As the purpose of constructing abstract concepts and theories is to enable us to better understand, engage with and transform the world, I'd like to move through these three meanings to propose - for those of us whose purpose centres on questioning and transforming increasingly pervasive neoliberal realities and imaginaries in education and wider society - talking about the 'critical postdigital'. Doing so to emphasise the intention to inform our practices and attendant relations (our praxis) as for radical democracy and eco-social justice.

The Three Meanings of Post: In the first meaning, 'post' can indicate a temporal, sequentially chronological dimension. The 'postdigital age' (Jandrić, Knox et al 2017) thus follows on from and supersedes the era or epoch of 'the digital revolution' (Negroponte 1998). Here, 'postdigital' symbolises changed realities or contexts which require a conceptual reconfiguration.

Building on this first meaning, the second and third meanings can be viewed as aspects of critique, as critically reflective responses to the digital. Thereby, the second meaning viewed as drawing on and evolving the insights of the digital, as following on from and building on, as in a 'continuation', albeit a reinterpretation or development of. And the third meaning viewed as, at least partially, in opposition to or in contradiction/tension with. Be that as a 'rupture' with or departure from the digital; thereby questioning its premises or assumptions as no longer, or perhaps ever, fully accurate or applicable. Thus, responding to, challenging and potentially transforming its premises and dominant underlying paradigm.

For many involved in contemporary dialogues on the topic (e.g. Jandrić, Ryberg et al. 2018), it appears that aspects of all three meanings are present. With the postdigital being conceived of as possessing a temporal aspect and as 'both a rupture in our existing theories and their continuation' (Jandrić, Knox et al. 2018: 895) - speaking to the third meaning, as tempered by the second. That is, as after and with (building on) but also against and beyond - a 'holding-to-account' of the digital' (Jandrić, Knox et al. 2018: 895).

The Critical Paradigm and the Critical Postdigital: For some, this aspect of the third meaning of 'post', as signifying an oppositional critique - a focus on what Jandrić at al. describe as 'the critical dimensions of the 'post' prefix' (Jandrić, Knox et al. 2018: 895) - is framed and oriented by a commitment to a wider, political project, situated within a critical paradigm (Jandrić 2017; Asher

\footnotetext{
${ }^{1}$ It is worth emphasizing the need to be wary of any implication as to homogeneity and the potential for Western/Eurocentric assumptions; to appreciate the uneven nature of the postdigital, both within and between countries, and realities as to degrees of (post)digital poverty and limitations as to access, agency and application etc. Which is not to suggest that there is any outside or outwith an increasingly globalized bioinformational capitalism (Peters 2012), rather that its impacts vary with respect to context, class and country.
} 
2018). One focused on working towards genuine equality and radical democracy in all spheres of society, as central aspects of eco-social justice (Amsler 2015; Giroux 2017).

It is these radically political conceptions of the postdigital that I believe we could term the 'critical postdigital', to provide greater clarity and emphasis as to a critical framing and orientation. The 'critical' qualifier serves to identify a specific cluster of meanings for the postdigital, explicitly foregrounding this critical framing and orientation (avoiding confusion amongst an increasing range of differing, contradictory and contested interpretations (Taffel 2016; Sinclair and Hayes 2018), and through doing so, locating a positionality for postdigital work/engagement as contributing to that urgent, wider, political project for radical democracy and eco-social justice. As such, drawing on and contributing to a constellation of 'critical' conceptions and theories, practices and relations, and related radical imaginaries - that speak to necessary resistances and alternatives to the hegemony of neoliberalism's state/corporate nexus and thus responses to our contemporary conjuncture of integrated crises (Haiven 2014; Chomsky 2017), including that of the university (Bacevic 2017; Hall 2018; Asher 2015). (Specifically, in such an educational context; critical communities, struggles, theories, practices and relations associated with critical pedagogies and popular education (Giroux 2011; Cowden et al. 2013; Crowther et al. 2005; Horton and Freire 1990); hybrid and critical digital pedagogy (Morris and Stommel 2018); critical academic literacies (Asher 2017); and critical university studies, (Williams 2012; Cantwell and Kaupinnen 2014; Morrish 2018) ${ }^{2}$. Not least, to address the inevitable dangers of co-option and recuperation by mainstream hegemonic discourse and practice, under contemporary neoliberalism's inherent and increasingly authoritarian trajectories; postdigitisation within bioinformational capitalism (Peters 2012: 105). The postdigital as subject to and forms of, thus both being shaped by and shaping, wider societal marketisation, commercialisation, financialisation and commodification - 'it [the postdigital] has already become commercialized' (Andersen, Cox and Papadopoulos 2014). As Morris and Stommel (2018) and Hall (2018) contend, this is clearly already the case for much of the new media and technology of education.

The critical postdigital provides a critique of both the digital and mainstream (capitalist) conceptions of the postdigital; 'as moving beyond, predominantly positivistic, digitally mediated capitalist social relations' (Peters 2015). As such, it contributes to ongoing educational and societal struggles and social movements working for eco-social justice and the development of genuinely democratic and emancipatory alternatives.

Thus the 'postdigital' provides one useful conceptual lens for describing and understanding our contexts and likely trajectories. And the qualifier of 'critical' provides an explicit orientation that speaks to resistances and alternatives to the intensifying neoliberalisation of both education and wider society. Drawing on Holloway (2016), the critical postdigital can be framed and oriented as with(in), against and beyond the digital and the capitalist postdigital. And thus, as one aspect of a wider, radical, political project, conceived of as in, against and beyond capitalism/neoliberalism - and with respect

\footnotetext{
${ }^{2}$ This is where the postdigital's focus on collective intelligence and knowledge making (Jandrić 2018; Peters and Jandrić, 2018) - as closely related to 'mass intellectuality' (Hall and Winn 2017), the 'democratic intellect' (Davie 1990) and 'conscientisation' as collective critical consciousness (Darder 2015; Roberts 1996) - and hence the collective democratic production of knowledges, values and desires, subjectivities and relations, can be seen to relate to and inform conceptions of genuinely radical or participatory, democracy (Amsler 2017; Bookchin 1990; Shalom 2008). Underpinning a political process focused on democratic participation, relations, practices and decision making across the different spheres of society (including education and research).
} 
to Higher Education; in, against and beyond the increasingly neoliberal university (Jandrić 2017; Hall and Winn 2017; Asher 2015; Canaan 2012; Cowden at al. 2013). And as for the radically different ways of living and relating, being and becoming, learning and thinking, doing research and education, that are necessary in an increasingly (post)digitally mediated world.

\section{Postdigital: the indirect, unseen, and absent digital (Jeremy)}

Central to the emerging theorizations of the postdigital is the curious notion that digital technology, on the one hand, has reached a point of such abundance as to become omnipresent, while on the other, precisely due to this banality, is disappearing, both into the materiality of our environment and the everyday unconscious of our lives. To claim we are straightforwardly in an era of 'ubiquitous' technology doesn't quite seem to capture this sense that 'the digital revolution is over' (Negroponte 1998), while at the same time seeming to be 'the master narrative of our world' (Fuller and Jandric 2018: 26). Further, how can we seriously engage with this notion of the postdigital, where many parts of the world, and many aspects of our social lives, do not seem very digital in the first place?

The problem here is overreliance on a rather simplistic model of direct access to digital gadgets as a measure of influence. To understand the postdigital condition we need to shift the way we view our relationships with technology, away from the engrained idea of individuals or societies making use of specific 'tools', and towards a more nuanced view of the character of our connections within broad sociotechnical systems. The precise and powerful contention of the postdigital is that one doesn't need to be on one's smart phone to be shaped by the digital. This might be identified through the immeasurable array of algorithmic agents that proliferate in the global financial system (O'Neil 2017), thus indirectly effecting economic prosperity here, and deprivation there, quite regardless of mobile network penetration, or our digital literacy levels. Further, one might avoid digital technologies as much as possible in one's professional role, only to be appraised through organizational data mining and analytics. One doesn't need to ever have had a Facebook account to find oneself inundated with articles about new media privacy and surveillance in the Sunday papers (e.g. Adams 2018).

The key point here is that, in order to develop a critical understanding of the postdigital, we often need to pay more attention to the influence of the indirect, unseen, and absent digital, and to understand our present, and direct interactions with technical paraphernalia, where we have them, as part of broader systems of relations, of which we are a part, but which don't necessarily fall into mutually exclusive user or used relationships. This encourages thinking, not about simple notions of empowerment, perhaps through 'personalized' media streams or access to 'free' educational content, but rather about the extent of agency within systems that have digital and non-digital actors (through which our entertainment or education might be better understood as merely the by-products of a much more elaborate data computation enterprise).

Future education needs to do more, not just to help produce tomorrow's users, coders, and data scientists, but also to encourage an understanding of our relationships with technology as reaching far beyond our screens. One of the important things signaled by the postdigital condition is that we can longer simply choose to be involved with digital technology. The question now is to what extent we are already entangled.

\section{The blabbering noise of individuals or the silent dialogue of many? (Derek)}

In her contribution to our first postdigital dialogue (Jandrić, Ryberg et al. 2018: 6), Sarah Hayes focused on the valences of dialogue, which, she says, can take two forms: first, 'the form of open, 
insightful and exciting interchanges,' and second, a form 'constrained if language is loaded with economically based assumptions and individualized agendas which restrict how we might collectively imagine alternative futures'. The latter form dominates educational research and practice, and thus with our new postdigital project we must question the value (exchange or use) we accord to dialogue. In order to overcome dialogue degraded by exchange-value, in other words, we have to overcome our own individual agendas. This is where our first postdigital dialogue failed.

In her short book, Whale Song, Margret Grebowicz (2017) confirms Hayes' call. Grebowicz identifies a paradox with environmental activism that we can generalize to our general postdigital condition. "As humans make their "voices" heard in the institutions available to them for what today passes for self-expression,' she writes, 'the world becomes literally - visually - nosier and nosier' (Grebowicz 2017: 75). To hear the whale song requires, among other things, silence, quiet. With so much noise it's difficult to hear, to truly listen. Exchange-value is, after all, solely about quantity rather than quality, and multiple individual agendas contribute more noise than collective ones. Academic exchange in the postdigital era thus faces key hurdles. Of course, much has already been written about the publish-or-perish regime. What I'm interested is the fact that our contributions are valued individually. We think of ideas as belonging to individuals (here I am responding to Hayes), or, at best, groups of individuals (which is different from collectives). When reading our first postdigital dialogue, I don't sense any real collectivity (Ford 2017). Instead, we have individual agendas that cohere at times and diverge at others.

At this point, I want to make one slight correction to Hayes' conception of dialogue. She explicitly writes that the first form is 'open,' which implies that the second form is closed. Indeed, in many ways the second form is closed: it's locked in the individual form, closed within the circuits of exchange, and subjected to the rule of exchange-value. Yet capitalism itself is an incredibly open system that not only accommodates, but thrives off complexity and openness (Ford 2016, 2019). Postdigital dialogue need not take closure as a value, but it must include an evaluation of the times and extent of which it should be open. We may have to think about the open and closed in a dialectical fashion. This has the effect of reuniting the form of dialogue with its content, which we also have to issue value judgments over: what should it be about, what and who should it be for? If we don't do this, we'll continue circling the drain of postdigital educational dialogue, contributing only individualized noise pollution and ironically inhibiting our ability to listen and form the collectives we need to conceive and materialize a different future.

\section{Postdigital reflexivity (Sarah)}

Around five years ago, I was struck by the surge of new stationery appearing on the market, surprised by the renewed popularity of planners and journals (Sheppard 2018). At the same time, whilst teaching my Sociology students, I noted with interest the array of devices and notebooks they brought to classes and supervision meetings. These individuals raised in a digital age, bore little resemblance (I thought) to the mythical 'digital native' (Kirschner and De Bruyckere 2017). They appeared to have adopted a hybrid approach using both digital and non-digital tools that (they told me) helped personal organization. Yet, learning involves more than these organizational aspects, that new businesses have now seized upon for increased capital (Sheppard 2018). A need for humans to make meaning beyond digital mechanisms alone has opened these avenues, revealing the social, economic and cultural trends that closely intermingle with the digital, since humans adopted the Internet.

Developing the concept of 'postdigital' and understandings of the human 'postdigital condition' (Jandrić, Knox et al. 2018) is both a shared endeavour and an individualistic inquiry. Yet, 
like any terminology, the 'postdigital' could also be considered jargon - just another expression put forward by a community that is difficult for others to understand. Already the rationale for the use of 'postdigital' has been examined (Jandrić, Knox et al. 2018) and the 'work' of the prefix 'post' in 'postdigital' has been considered (Sinclair and Hayes 2018). At risk of adding to potential accusations of jargon... I now propose that 'postdigital reflexivity' might also be explored, as a developing practice. By this I mean an ongoing, critically reflexive interrogation by each of us, into the notion of 'postdigital' as a proposition we are adopting and adapting. Particularly, if I use it to further meaning, for example, concerning the journal habits of my students...

The origins of a theory and the social circumstances of its creation are important because the 'genesis of an idea is deeply social' too (Mills 1940: 319). Even 'jargon' can itself be described as jargon and the notion of a 'buzzword' is itself not above scrutiny. To be critically reflexive is to honestly acknowledge our own human 'role of positionality and subjectivity' (Dean 2017:1) in how we adopt and apply words, such as 'postdigital'. We may seek new connections through the 'postdigital' in the belief that the 'digital' has wrought forms of separation, but without reflexivity, the 'postdigital' may divide too.

Whenever a word or phrase becomes objectified, it is distanced from humans, unless we continually point to its subjectivity, origins and political interests. The same principle applies to technology. Elsewhere, I have argued for a close scrutiny of higher education policy discourse, such as 'technology enhanced learning' and 'student engagement', for these reasons (Hayes 2019). So, for the sake of provocation: what makes the notion of 'postdigital' any different? When we 'do reflexivity' (Dean 2017) subjective spaces that reconnect humans are opened. The 'imperfections' of the 'postdigital' have already been acknowledged, but this may not be enough, if we do not practice (and interrogate) approaches towards 'postdigital reflexivity'.

\section{Paradigmatic patterns of knowledge production in the postdigital humanities (George)}

The urgency to operate technical products and clarify the limitations dictated by technical tools shapes the manner in which knowledge and meaning are generated. Any rigorous methodological approaches to the postdigital humanities would paradigmatically back the creation of meaning above and beyond of operational postdigital products. The postdigital humanities is characterizable through synergy, partnership, cross-fertilization, and disagreement with similar disciplines. To comprehend the postdigital humanities, the underlying character of postdigital culture and society should be apprehended. Humanist incongruity in relation to computing indicates positions in wider society, and is triggered by the same ontological anxiety. Even though computers are concrete physical objects, they perform at a degree of elaboration that misperceives normal connections and encourages dialogue. Computers are tools that are incorporated in human society in elaborate but not unquestionably pivotally important ways. A purposeful rise in technical capability, associated with a resourcefulness in employing postdigital tools and methods and creating postdigital goods (Mirică (Dumitrescu) 2018) is frequently correlated with a decline in significant requirement of computational technologies. Knowledgeable postdigital humanists acquire implicit proficiency about how first-rate postdigital products are created, comprising standard procedures in software engineering and programming, technical demands necessitated for academic outputs, initial inspection of user groups, and the character of operational and ineffectual preconditions. The postdigital humanities community is impacted by disparities in the worldwide scientific cooperation surpassing computing culture or the postdigital devices it employs. The postdigital humanities 
provides a test site indispensable in examining the consequences of computing for humanistic construals of the world (Smithies 2017).

The postdigital humanities represents the utilization of computational criteria, processes and devices to humanities contents: it should provide theoretical interventions and postdigital approaches for a historical stage when the algorithmic has become both prevailing and post-screenic. The postdigital humanities is unprecedentedly disposed between technology and culture, analyzing judiciously how the tempos of the computational are performed and actualized. The postdigital humanities should advance to eulogize the established values of the humanities and should intensify its integral comprehension of computer technology and its related routines. Without an incisive analytical introspection, postdigital humanities is unsuccessful in its standardizing capacity to influence the broader humanities, in addition to its useful contributions. The postdigital humanities may be instrumental in a rigorous analysis of culture and society (Mitea 2018) that links to the dynamic fashions in which culture is churned out, consumed, assessed and distributed in intricate computational societies. Text has an archetypal role in postdigital humanities work. Knowledge portrayal and encoding as a series of routines are a considerably relevant component of postdigital humanities. Postdigital humanities can be decisive to a scrupulous reflexive community that can employ its computational grasp in public society, politics and scholarly knowledge production for the common good. The consistence and the semiotics of postdigitized works constitute the basis of postdigital humanities that should participate in significant design undertakings (Peters and Besley 2018) to set up alternatives to the present computer systems. Postdigital humanists should improve their capacities of evaluation in relation to sites of power, encompassing the mental representation of postdigital technologies, platforms and infrastructures (Berry and Fagerjord 2017).

\section{Postdigital Education}

\section{Changing the world with finger prints: the postdigital, bio-informational capitalism, and education (Liz)}

'Postdigital science and education' (Jandrić et al. 2018) takes readers beyond the concept of the digital, reminding of the significance of biology to twenty-first century knowledge practices. As Peters (2012) notes, bio-informational capitalism invokes the physical (digital) and biological (nondigital), as technology challenges are economic and political (Jandrić et al. 2018: 894). Articles like this, which aim to develop the concept of postdigital, are urgently required today.

This last week, I operated for several (work) days without my own computer, laptop, or mobile phone. Before this event, I prided myself on being able to live, and enjoy, life, without these devices. Ten years ago, the idea that any of them were required was just emerging in (post)modern societies. Yet in these last few days I experienced a feeling of deficiency. Not being able to access distributed data and information and engage with others from anywhere, anytime, made me feel vulnerable, lacking, guilty, anxious, and confused. A sense of urgency accompanied these feelings, that this situation needed to be rectified as soon as possible, lest it hurt my productivity. I found myself apologizing and explaining to colleagues. To be without finger-tip access to others is now akin to being in another country without roaming or great Wi-Fi. It is a problem; a risk.

That a professor (or student) is incomplete without regular and 'natural' online access has been touted in the digital age as a good thing. There is convenience and customer service. But it has a cost to bodies which used to have independence and autonomy, historical values of academia (Berg and Seeber 2016). 
That the postdigital is more than digital, and biological, also comes to mind when observing the nefarious uses of big data. Today I can book a holiday, order pizza, or do any number of tasks on my phone through finger print identification. Yet my phone also records and shares with others how often I tap, open, use, hold, unlock, and set aside my phone and use apps. Websites and apps which track usage code this data, to recognize if I am an anxious or leisurely user; if I am suggestible or not, in relation to news sources, fake news, or social networks. Companies claim this data is being used to improve experiences. However, it has also been used in recent years for partisan political purposes. Our finger prints are the new 'carbon footprints', as public relations firms mine human data to change the course of elections, and thus global political, economic, and ecological realities.

I applaud Jandrić et al. (2018) for building up new concepts such as 'postdigital'. Such work is needed to politicize the digital and the biological, and illuminate the material realities of an unfolding world of data and information. It is also a call for developing new understanding of what it means to be researchers, educators, and youth in a world both online and offline, which is messy and often depoliticized. As finger prints change the world, the move to the postdigital is timely.

\section{Postdigital education: a common good (Julia)}

Our contemporary conjuncture is complex and pregnant with algorithms (Peters and Besley 2018). There is a tendency to view the digital as an essential concept that interacts with our ways of developing as human beings. Living in a world where the digital sphere and its borders are blurred, it seems important to look back and make a deep reflection about our current condition, which is whether we want it or not - a curious combination of the digital and the non-digital. For the lack of a better term, Jandrić, Knox et al. (2018) (and other authors) call it postdigital.

The postdigital is not static, it is a highly dynamic process which evolves and grows every single time that we think of interactions between digital technologies and our 'original' nature. Conceived in US military laboratories, claims Tim O'Reilly (in Osuna Acedo et al. 2017), the Internet has nevertheless enabled wide participation, new democratic opportunities, community development, and informal learning. In the postdigital age, 'it is clear that contemporary networked learning is becoming increasingly more diverse' (Jandrić, Knox et al. 2018: 895). It also takes place everywhere, so in the postdigital era we seem to be entering the era of ubiquitous learning where people teach and learn simultaneously in so called 'affinity spaces' which, to an extent, resemble popular culture (Jenkins 2008).

The view to students as active subjects in teaching and learning processes is one of the main principles of Freire's pedagogy. According to Freire (2005) we all are educators and pupils at the same time; this relationship expands to the digital context and beyond (McLaren and Jandrić 2014; Jandrić and Boras 2015). That is why the postdigital is 'considered as an extension of Paulo Freire's pedagogical model' (Jandrić, Ryberg et al. 2018: 7). Education is much more than transfer or generation of knowledge and skills (Giroux in Peters, Rider, Hyvönen and Besley 2018: 204); more importantly, it is also a preparation for participation in a common social project (Delors 1996). Educational policies and educators have a huge responsibility for generating participative cultures and critical pedagogies aimed at learning and building a democratic society based on dialogue and participation (Kaplún 1998).

Today's postdigital spaces, online and offline, are being regulated by technical design and politics. By and large, education and knowledge development are commercialized and instrumentalized (Bauman 2008; Delors 1996; Deng, Benckendorff and Gannaway 2019; Wakefield et al. 2018). A 'critique of digital reason' is a term, adopted by an increasing number of today's 
critical theorists, that takes into account the control systems and political economy behind the postdigital reality (Peters and Besley 2018). We now face a significant challenge of claiming the postdigital sphere as a common good which belongs to everyone and where everyone is represented - including non-human actors such as animals and artificial intelligences (Jandrić 2018). Freire's (2005) message that education must aim at transforming the world, and the work of his successors claiming that common education needs to work in favour of social justice (Escaño 2013), now needs to be updated in and for the postdigital reality.

\section{Schooling and the postdigital (Rachel)}

When considering schooling and the postdigital, a tension is evident. On the one hand, students, teachers and schools can be understood as being postdigital. On the other hand, however, education policy and curricula indicate a continued push to further embed digital technologies in schools. Policy rhetoric betrays a fear that students are not being adequately prepared for participation in a global digital economy and are not being given enough exposure to digital tools. This section contrasts the postdigital with policy rhetoric that suggests that school systems are not yet digital enough - let alone postdigital. Given the increasing uses of digital technologies for surveillance and accountability within education systems it could be argued that the policy rhetoric operates as a screen obscuring the degree to which digital technologies are reshaping education systems.

The dominant policy discourse regarding educational technologies sees the addition of educational technologies in classrooms to make learning more efficient for students and easier for Australian teachers (Department of Education and Training 2018) and as a way of preparing students to work in the global knowledge economy (Buchanan 2011). With the assumption that technological skills are essential for economic participation digital technologies are now a policy requirement in the provision of schooling in Australia (ACARA n.d.) and other nations globally. For example, the latest review into education in Australia advocates more use of digital technology for improving the school system. The need for continuous improvement is justified on the basis that

Australian jobs and industries will be reshaped by revolutionary technologies, such as artificial intelligence and automation. These technologies will decrease the need for lowerskill, routine work, and increase the importance of problem-solving, collaboration and interpersonal skills. [...] We need a world-leading school education to equip Australian students to take advantage of these opportunities. (Department of Education and Training 2018: 3-4)

While policy documents read as though schools need to increase the usage of digital technologies, many children (in highly technological nations and wealthy contexts) can already be considered postdigital. Young children incorporate digital technologies into their play, and this is now part of the way that they learn about the world (Edwards 2013). Older children and adolescents not only have high rates of ownership of digital technologies such as tablets, iPods and mobile phones but they use social media as part of their identity formation via 'public displays of connection' (Boyd and Ellison 2008) and the creation of a profile on social network sites to 'type oneself into being' (Sundén 2003: $3)$. The traditional narratives of identity and agency available to young people 'are being complemented by new possibilities that are the direct outcome of their participation' (Mallan 2009:

53) in a postdigital world. 
Not only is there evidence to indicate that students are postdigital, in contrast to policy rhetoric that suggests that school systems need to make more use of technology, examination of the school systems use of digital data collection suggests that these systems can already be considered postdigital as well. Consider the following: teachers' work has been datafied via professional standards accreditation processes that make them countable, measurable and able to be ranked (and not just through data generated about their students, but against the data that they themselves must produce about their professional development) (Clarke and Moore 2013); Learning analytics platforms are increasingly being used in schools. These are designed to 'mine data about learners as they go about educational tasks and activities in real time and to provide automated predictions of future progress that can be used as the basis for intervention and pre-emption' (Lupton and Williamson 2017: 785). Students are being continuously monitored in a multitude of ways, including their progression from preschool to further and higher education, their physical activity, use of digital devices, social media, and their physical location can be recorded in perpetuity as well as tracked in real time.

These varied uses of technology mean that students have become more enmeshed in an 'everintensifying network of visibility, surveillance and normalization', where the 'embodied expert judgement' of their teachers is displaced by disembodied algorithmic and adaptive decision-making technology (Lupton and Williamson 2017: 786-787). The risk in such education systems is that such processes shut down educational possibility and that students' prior actions determine the future learning made available to them. Policy rhetoric that suggests that more technology is needed to ensure the development of successful systems of schooling serves to obscure the degree to which education is already postdigital, and the ways in which technology is currently exercising control over students and teachers. A postdigital exploration of education allows for a nuanced exploration of the effects of such uses of technology, rather than a continued myopic focus on embedding digital technologies in schools which 'make us overlook that contemporary student practices with technology are complex entanglements between physical and digital technologies, spaces, activities, and time' (Jandrić et al. 2018: 896).

\section{The Critical and Ethical Postdigital (Laura)}

In terms of its educational possibilities, the postdigital offers more than we can currently possibly imagine precisely because the prefix 'post' paves the way forward into the future and is ongoing (Jandrić, Knox et al. 2018). The educational environment has not kept up with current technologies and is at risk of falling even further behind as technological changes continue to occur at a rapid rate (D’Olimpio 2018). With the technological infused into the world, our bodies and permeating the way we connect and communicate, Web 2.0 is always interactive and never static. Users are also content curators and creators, whose traditional skills of literacy and numeracy must be flexible enough to effectively make use of the technology at our disposal and be ever prepared for the new and innovative. A useful approach for educators is to remember that although digital natives have grown up with this technology and it is second nature to them, this does not necessarily mean that young people know how to use such technology critically or ethically; with care and compassion for both themselves and others with whom they interact. The ethical questions seem to come later, too late, after the moral dilemmas have arisen, and yet it is vital that we initially critique and query how we wish our lifestyles and our world to be transformed by the digital and by technological innovations. Placing human considerations and the ethical at the centre of the discussion is something that may be taught in a classroom setting, whereby a 'safe' exploration of important ideas may be enabled via genuine dialogue. 
As the postdigital 'tends to focus on the experiential rather than the conceptual' (Andersen, Cox and Papadopoulos 2014), it is imperative we ask the question about what kinds of experiences we want, rather than passively going along for the ride and then afterwards complaining about motion sickness. As the postdigital space 'already has become commercialized' (Andersen, Cox and Papadopoulos 2014), we need to consider the consumer power and impact the masses may have in asserting what we want and what we value: whether that is hedonism or compassionate global citizenship; whether it is economic gains at the expenses of others or policies that support climate change mitigation. These options (and endless more) need not be binary oppositions, but the few in positions of power will only listen if the masses learn how to communicate such priorities in a way that will be noticed. Hence why education is vital in the postdigital age.

In a postdigital space, literacy is multiple and must go beyond language in order to include culture and context (Cope and Kalantzis 2000: 5) and, now, code. As such, literacy is 'embedded in multiple socially and culturally constructed practices' rather than as a 'uniform set of mental abilities or processes' (Gee 2009: 196). In order to engage well with multiliteracies, one must adopt a critical and moral disposition flexible enough to take into account the variety of contexts and perspectives presented by a range of media (D'Olimpio 2018: 76). When considering the impact of globalisation on curriculum and pedagogy, educationalists face two main concerns. Firstly, how to teach learners to be global consumers or citizens. This includes a focus on global values, social justice, sustainable development and environmental education (Edwards and Usher 2008: 53). Secondly, the impact of informational technologies and the emergence of global education as a result of such technology. Herein lies the hope of a democratic accessibility to information, yet we must not forget the interaction between the global, the local, and the regional. As digital 'voices' multiply, postdigital educational spaces are no longer closed and fixed and this is echoed in the way we now speak of meaning-making, rather than 'meaning', as participants interact in order to jointly construct and coconstruct meaning. The optimism 'about the potential of global technologies to create information democracy and low-cost access to a whole range of knowledges' (Cunningham et al. 1997: 160, quoted in Edwards and Usher 2008: 65) will only be realised if a central space is established for education that includes the exploration of ethical questions pertaining to the postdigital.

\section{Postdigital smartphone addiction and nomophobia: we need to talk about Jumbo (Mark S.)}

They did extraordinary tricks, showed you things you hadn't seen, were fun. But came, through some gradual dire alchemy, to make decisions for you. Eventually, they were making your most crucial life-decisions. (Gibson 2010: 53)

Mouthed by the central character (Milgrim) in Zero History (Gibson 2010), William Gibson's reflection on addiction in an iPhone-obsessed world speaks to postdigital education. I speak as a creative practitioner who teaches and researches in the field of digital arts. Working with students, I have witnessed the emergence of a mindset within the studio classroom that does not question use of smartphones; does not critique algorithms that direct 'independent' research and idea generation. Stroking one's touchscreen has become 'an integral part of our lives', indicative of growing dependency, 'if not addiction' (Hartanto and Yang 2016: 329). Like many who work in education (including the students themselves) my regard for digital technology is conflicted. For myself, the daily grind of sifting through the detritus of my email in-box is balanced by my unending appreciation of its creative facilitation of my research, writing and film-making. Peter McLaren describes this 
duality as a simultaneous loathing and addiction to technology (in Jandrić 2017: 190). It is this notion of the postdigital 'addict' that I would highlight, alluded to by Negroponte: 'being digital will be noticed only by its absence, not its presence' (Negroponte, 1998).

Written a decade prior to the release of the first iPhone, Nicholas Negroponte's interdisciplinary approach to research and thinking resonates with the need for meaningful debate about our use of mobile digital technologies within educational contexts. Nomophobia (the fear of being without smartphone connectivity) is rife, with students regularly describing their usage as an addiction and research that indicates a dip in cognitive reasoning when students are temporarily disconnected from their smartphone (Hartanto and Yang, 2016; Mendoza et al, 2018; King et al., 2014; Yildirim and Correia, 2015). The ubiquity of the smartphone and its potential to affect students' cognitive behaviour has emerged as what I identify as the virtual elephant-in-the-room. Our postdigital 'Jumbo'. For many educationalists, be they an academic researcher, a school principal, or a teacher establishing the parameters of students' daily technophilia, phenomena that may be associated with addiction to smartphone fuelled postdigital existence has reached a hiatus that requires a dialogical solution.

As a lecturer in the creative arts I have witnessed nomophobic responses to smartphone deprivation, ranging from nervous tics, to anger. Such a range of physical and emotional manifestations of nomophobia correspond to research findings that identified common areas of anxiety, such as 'not being able to communicate'. It is this feeling of disconnectedness with their immediate environment that, above all else, lends a sense of addiction to many students' use of the smartphone, and calls for the 'elephant-in-the-room' to be named and subjected to open, democratic and critical dialogue. We need to engage with smartphone usage. In postdigital societies, touchscreen technologies enable participation and knowledge transfer. Do smartphones also disenable a high percentage of students? In a postdigital misle that blankets us with those half-truths and lies that garner our attention, are we capable of highlighting the need for critical dialogue about smartphone usage and its addictive properties? As critical educationalists, if we insist on supporting students' location of this virtual Jumbo in our classroom or studio, then we must also ask ourselves: are we capable of assuming the mantle of the addiction counsellor?

\section{Postdigital praxis in a sociology class (Juha and Olli)}

One way to avoid the danger of 'postdigital' becoming another academic buzzword, an empty signifier, is to connect it to a human endeavor, i.e., educational praxis. In our pragmatic view the concept must be embedded into and have a counterpart in a certain practice for it to be meaningful and sensible. Following Ludwig Wittgenstein's suggestion that 'the meaning of a word is its use in the language' (Wittgenstein 1958 paragraph 43), in this short text we briefly describe our experimental academic teaching practice.

The more we have taught in the university the more we think our teaching as a postdigital practice mixing 'meatspace' and 'cyberspace'. In the fall semester 2018 we mentored together a BAlevel sociology course on the sociological imagination in the spirit of C. Wright Mills classical work The Sociological Imagination (1959). Instead of using our university's password protected Moodle learning environment, we launched a (Finnish language) Wikiversity course page as our digital platform (https://fi.wikiversity.org/wiki/Wikiopisto:Etusivu). The multilingual Wikiversity is a free, open-access, and easy to use learning environment for all operated and administered by Wikimedia Commons Foundation (see Suoranta 2010; Suoranta 2012; Suoranta and Renfors 2019). 
In the planning stage we defined our role as mentors or facilitators who would not lecture (too much) but organize and in a way 'curate' the learning and group work of students. Keeping in mind the general theme, we designed the contents of the course in a manner that would best give the students and us alike opportunities to cultivate our sociological imagination. In the first class we introduced our Wikiversity course platform containing the weekly schedule, reading materials as PDF files, and Internet links. The students formed groups for weekly assignments, and each group created a subpage to the Wikiversity page for them to share their report their discussions and share their ideas with the rest of the class. After the introductory session we had the following themes once a week: the promise of social science, intellectual craftsmanship, paradigms (or chronotopes) of social science, the study of personal experiences, sound and the visual (in social media) as sociological data and study objects, and, finally, the intersections of literature and the sociological imagination. We gave the groups flexible and open-ended assignments, and asked them to ponder the themes from the point of view of the sociological imagination. And they did! Often their insights were spectacular.

The course was very much a flipped classroom in that the students had their autonomic group meetings during the week. In the group meetings they fluently used both the digital resources of the Internet (e.g. Instagram pictures, Youtube videos) and the university library (e.g. scientific papers, academic thesis and books), discussed the themes with each other and prepared for the next week's class. Every group wrote (copied and pasted) their thoughts, insights, links, and questions on their individual Wikiversity page before the classes. In the class we shared our insights and began to act simultaneously as teachers and students in a Freirean spirit (Freire 2005: 72). Inside and outside the classroom we became a group of people who shared a concern and were passionate about a topic, and who along the way deepened each others' knowledge about the possible and perhaps impossible interpretations of sociological imagination.

Based on our teaching experiment we emphasize the postdigital as a form of 'community of praxis' in which praxis refers to reflection (group and classroom discussions) and action (organizing groups work and writing wiki comments), and suggest that in educational - or perhaps in any other social settings the 'postdigital' refers to a) the multiple use of both digital and traditional information as an ordinary practice, b) the mixing of digital and face-to-face interaction inside and outside the classroom, c) the fruitful solution of the teacher-student contradiction, and d) the expansion of learning via open digital platform such as Wikiversity.

\section{Postdigital practices in students' work (Thomas and Jacob)}

In the editorial for Postdigital Science and Education (Jandrić, Knox et al. 2018) it is initially stated that 'We are increasingly no longer in a world where digital technology and media is separate, virtual, 'other' to a 'natural' human and social life' (893) and that 'student practices with technology are complex entanglements between physical and digital technologies, spaces, activities, and time' (896). This is thoughtfully explored in the inaugural issue by Fawns (2018) who equally argues for the inseparability of the digital and the 'natural' and social life. In this brief commentary, we share an empirical example illustrating the intertwined nature of the digital and non-digital to add some flesh and blood to this general idea. The example stems from our field work within the past five years, where we have explored students' use of digital technologies as part of their problem-oriented project work in Aalborg University (Ryberg, Davidsen and Hodgson 2018). In particular, we have observed students from the programme Architecture and Design (A\&D) and have had the opportunity to videorecord substantive amounts of video-data of their everyday work in their studios located on the same floor. In the course of the observations, we learned that students - apart from sharing physical spaces 
- equally shared ideas and designs through a Google+ group and via Pinterest (the former initiated by the teacher coordinating the semester). The students can thus explore design ideas of the other groups by walking around visiting the other groups physically as well as online and get inspired by others' work.

In one of the groups, the design ideas they collected on Pinterest were printed and physically hung on wires in their studio. As their project progressed, the printed design ideas were replaced and re-organized, but remained there as a 'suspension bridge' connecting the physical and digital aspects of their work. In our field work we have come across numerous examples of such transpositions between the physical and digital. This illustrates that when we, as researchers, look closer at students' actual practices with (and without) digital technologies we may encounter many such bricolages or patchworks where the digital and physical materials and resources are intimately woven together in creative manners. It shows glimpses of how the students are not working in separate or distinguishable realms or realities, but how the digital and physical are continuously mixed and braided together forming knots that cannot be easily disassembled into discrete parts. In this manner, the students are engaged not in digital or material practices; rather their practices are in many ways postdigital understood as complex socio-material entanglements of the 'digital' and 'physical' rendering the very distinctions between the two problematic.

\section{Postdigital Identities}

\section{Unsiloing identity: the need for a postdigital identity theory (Anne)}

I sat with a group of psychologists, one educator in a sea of therapy-speak. The case being staffed involved an adolescent student with limited language skills. One therapist reported that the student exhibited certain areas of deficit, yet also noted that he spent an inordinate amount of time on his phone, supposedly playing games. As the case was discussed, clinicians around the table asked questions. Was a particular test used for assessment? Was a particular score within normal range? Was a particular diagnosis considered? I listened to all of this, wondering if I had missed something. Finally, I could contain myself no longer as I asked, 'What was he playing on his phone?' It seemed to me that this student was showing motivation, connectivity, and some sort of possible mastery - all of this at a time when these three inner competencies seemed to be called into question.

If postdigital education and experiences reveal anything, they show that we are changing the world with technology. But technology is also changing us. The obvious changes are social, political, educational, and more (Jandrić 2017). This leaves me wondering about psychology, though, and theories of identity. It might be possible that we need postdigital theories of psychological development to account for how students today might be different, psychologically, from previous generations. Or - perhaps - how we all are different in this postdigital age. A reconsideration of psychological identity theory through the lens of postdigital realities is not to be confused with digital identity theory. There are plenty of digital identity theories that parse how students form their online identities. Digital identities, broadly, can be conceived of as both process and product (Poletti and Rak 2014), malleable and fluid, constructed according to social need (Ahlquist 2015), yet concrete enough to be stolen (Sullivan 2018).

Identity theories are too numerous to include here, but current theorists who speak to college student identity are Jones and Abes (2013), Torres, Jones, and Renn (2009), and even Zhao, Grasmuck, and Martin (2008), to name a few. Although there does not seem to be one fluid theory that accounts for postdigital realities, precedent-setting scientific findings lean toward the 
development of such theories: experience marks the brain, making profound alterations (Carrion, Weems and Reiss, 2007; Flacone 2013); the brain changes from digital exposures, especially in adolescents (Crone and Konijn 2018); and epigenetic research tells of the interplay of biology and environment (Toyokawa, Uddin, Koenen and Galea 2012). These three strands weave a whisper that perhaps there are developments in the brain that transform identity. At the very least, this seems like something to consider.

Jandrić, Knox et al. (2018: 895) called for a 'critical understanding of the very real influence of these technologies as they increasingly pervade social life'. I wonder if part of that critical understanding is the development of our understanding of postdigital self. Junco (2014) described online identity at three levels: true identity (a profile that reflects demographic information), pseudonymity (created demographics, like a handle), and anonymity (no or obscured demographics). This type of analysis, though, splits people into digital selves and demographic selves. These siloed identities continue to walk separately, albeit arm and arm. Fawns (2018: 4), in describing education, describes 'all teaching as incorporating digital and material activity', in recognition that the boundaries between humanity's activities cannot be so formally drawn. As binaries begin to fade in postmodern, anti-oppressive philosophies (Kumashiro 2015), these digital/material, virtual/actual separations dissolve into continuum. Fawns (2018) reflects, 'Thus, in discussing postdigital ideas of education, I am looking less for a linguistic shift and more for a shift in educational culture.' Precisely the type of idea I am considering for identity theory. Not an additive 'digital identity' but a shift in psychological thinking that embraces and interrogates postdigital psychology - how are we changed, at our very essence, in this time, and how are children who are born into this postdigital time looking at and experiencing their worlds? Feenberg (2019: 1) notes, 'The postdigital no longer opposes the virtual or cyber world to the world of face-to- face experience.' Perhaps this integrative stance is one which psychological theorists and researchers can also consider.

Postdigital discussions lend themselves to topics of humanity, theology, and the social sciences (Fuller and Jandrić 2018). However, if we don't reframe psychology in light of postdigitial realities, we risk talking around students instead of stepping into their new paradigms, their social virtual realities, their third spaces of engagement. Instead of cobbled hybrid psychosocial identity theories, we might need reconceptualized postdigital psychosocial identity theories to provide the way into the new world of an adolescent living in a postdigital reality.

\section{Postdigitally networked self-representations of girlhoods, virtual social identities, and online textual routines (Ramona)}

Cultural interpretations of gendered selfhood are influenced by the literary and media frameworks in which they are created and employed. In postdigital economy, girlhood may be fluid. Girlhoods, as hyper-apparent, impenetrable and regulated grounds upon which expressions of bloom and gender combine, take up a burden of cultural gear as their authors travel through the super-imposed areas of online and offline realms. Such acts of self-narration are induced, facilitated, and regulated by the postdigital networks of production and utilization in which they navigate. A variety of automedial images take place in dialogue with and connection to one another, traversing media platforms and using a multitude of automedial strategies. Juvenile femininity is located in networks of textual manufacturing and consumption (Roca-Sales and Lopez-Garcia 2017) that are cut across by expressions of gender, girlhood, and the commercialization of self-presentations. Commoditized and objectified, well-preserved feminine self-brands advertise girlishness. The display of factualness is questionable and the identity being formulated in self-referential contexts necessitates additional 
inspection. Autobiographical acts are established socially, within groups that can comprehend the identities exhibited through mentioning shared or designated meanings and values concerning personality and self-narration. Girls' nonfictional media have target markets and niches that affect how they disperse and are received, defining the types of girlhood subjectivities that are portrayed. Such texts are articles of trade that are incorporated in arrangements of production and consumption, making discernible the exigencies and frictions that typify the arcade for girls' self-representation. Girls' autobiographical content is literary and media pieces that perform cultural work (Mihăilă and Mateescu 2017), and that involve approaches of self-narration in which they decide on exemplification, mediation, and narrative architecture. Life description is a scheme that disregarded individuals employ to integrate themselves into culture (Maguire 2018).

The current postdigital setting offers appealing opportunities for girls to produce substantial autobiographical fiction. Subjectivity and distinctiveness spread and operate in promising modes of performing postdigitally. The emergence of postdigital user-generated media has altered the array of available representations (Jouët 2018), making possible fashionable kinds of autobiographical subjects. Girl-authored media develops from the perimeters of a reality-insatiable media environment in which teenagers have taken advantage of a series of media tools with the intention of producing, displaying, and advertising their self-representations. Automedial routine may be instrumental in redesigning the media setting where apparent reality materializes as a relevant entertainment product. An automedial self may encompass a choice of interwoven postdigital contents that may disseminate autonomously, but that also team up to establish a personal brand. Such routines of self-mediation and networked nonfictional commitment may clarify how postdigital spaces are defining ongoing ideas of self. The contexts and crossing points in which postdigital texts prevail are evolving swiftly, changing the way such pieces are accessed and made known. Subcultures, and the contents that spread within them, resort to more far-reaching cultural trends of meaning and power and thus determine the types of subjectivities that are brought about for the girls who are experiencing this (Maguire 2018).

\section{Postdigital Māori science and education (Georgina)}

Digital technologies are central to our lives and efforts to re-seed and revitalise our indigenous languages and cultures in the $21^{\text {st }}$ century. This world has become postdigital - a word pointing to the embeddedness of digital technologies at all levels, from personal to global (Jandrić, Knox et al. 2018). Māori have been early adopters of new technologies. How does the embeddedness of digital technologies both help and hinder Māori aspirations for te reo and tikanga (Māori language and culture) within research, the academy and education?

Firstly, digital tools for Māori language learning and information on Māori topics are rapidly growing and diversifying, including apps (Hika Group 2018), online dictionaries (e.g. Wordstream 2018) and repositories (e.g. New Zealand Digital Library 2018), school resources, support groups, etc. These developments are supported by the legal status of Māori as an official national language (New Zealand Legislation 1987). While in theory these digital tools are available to everyone, access depends on having things like a computer and internet connection. The Māori population is concentrated at the impoverished end of the socio-economic scale, which means many Māori people are prevented by cost barriers from benefitting from the postdigital age: digital embeddedness cannot overcome economic inequity. A Māori-centric perspective is (or should be) more aware of the 'underdog' view and therefore (arguably) more inclined towards critical thinking about the effects of postdigitality. 
Other developments characteristic of the postdigital age are taking place in knowledge regimes such as publishing. Until recently it was nearly impossible to publish books or journal articles written in Māori. Publishing norms insisted all Māori words had to be italicised as 'foreign'. These rules have been overturned by Kaupapa Māori attitudes and assertion of Māori political rights in the symbolic public domain and media. Facebook enables new forms of old practices such as whanaungatanga (maintenance of kin-group relationships). Critical sociolinguistics considers normalisation of endangered languages like Māori as valid language rights (May 2012). Māori language publishing is currently in flux in the digital publishing environment, catalysed by the digital tools described above, with bilingual and Māori-only books appearing in the last few years (McFarland and Matthews 2017; Olsen-Reeder, Hutchings and Higgins, 2017).

Postdigital science also signifies methodological innovation in research and postdigital Māori science suggest new methods and ideas in Māori research. Science influences all research and residues of scientism (Sorell 1991) persist in qualitative research, especially in fields like psychology of education. Therefore postdigital science also means the exposing and ejecting of these ideologies, which links it to critical theory in research and research methodologies, and aligns with Kaupapa Māori research principles.

For Māori, the idea of 'postdigital' as a return to the 'pre-digital' has a literal connection to oral language forms and traditions. Novel forms of research such as expert dialogues, critical conversations (Hoskins and Jones 2017), narrative research (Stewart, Tamatea and Mika 2015) and video research (Stewart and Dale 2018) are useful postdigital methodologies for Māori-centric research. We can expect to see a burgeoning of Kaupapa Māori video research in the next few years. In each case these interdisciplinary methods have theoretically to cross the boundary from data collection to analysis, which involves the quality of being 'theory-generating' (Bogner and Menz 2009). In this way Māori research interests cover the postdigital terrain, from knowledge recovery to knowledge production.

\section{Conclusion}

\section{Let us not forget - the digital (Mark D)}

At a conference in 1988, in a brief and largely improvised talk given as an introduction to a paper by the psychoanalyst René Major, the philosopher Jacques Derrida remarked that the impact of psychoanalysis on the philosophical discourse of the 1960s and 70s resembled, in some way at least, a traumatic experience. For Derrida, this was a period when psychoanalysis 'had pushed philosophy far away from the centre, obliging philosophical discourse to reckon with a logic of the unconscious, at the risk of allowing its most basic certainties to be dislodged, at the risk of suffering the expropriation of its ground, its axioms, its norms and its language' (Derrida 1990: 4). Psychoanalysis, then, was a traumatic event which had disorientated philosophical discourse; something which shook the supposedly secure reason upon which most of it was based, and which appeared to expropriate philosophy from itself. What was interesting for Derrida, however, was the way that such discourse reacted, in that it seemed to imagine that the traumatic interruption of psychoanalysis had never happened: 'people are starting to behave as though it was nothing at all, as though nothing had happened, as though taking into account the event of psychoanalysis, a logic of the unconscious, of “unconscious concepts”, even, were no longer de rigueur' (Derrida, 1990; 4).

Reading the editorial for Postdigital Science and Education (Jandrić, Knox et al. 2018) I was reminded of Derrida's suggestion and wondered if there has been something similar happening in the 
reaction to the digital. In, for example, Negroponte's claim that it might be all too easy to take the digital for granted, as that which is 'noticed only by its absence' (Negroponte 1998). But I also wonder if that response is itself a little too simple, and that what could also be happening is a certain double movement, mechanism or schema, whereby the very forces which are trying to forget or overcome the impact of the digital - in order to return to some form of stable or solid territory, or authoritative position of knowledge, foresight, power or control - are summoning the digital in order to eliminate, repress or ignore it (in a similar way that an exorcist might summon the very thing that they claim to eradicate). This would, of course, mean that all those reconstructed positions of authority and stability are put into question by the very term which they have supposedly conjured away, but which, in fact, no one can really claim to fully understand.

The nuanced and varied comments in this collaborative article are, for me at least, a retort to what could be an almost mechanical response to, and repression of, the digital. What they signal instead, is that we are not done with the digital, and indeed, that what the term postdigital might mean, if it means anything, is not so much a period in which the digital has become commonplace, but rather the recognition of a responsibility to affirm its profound complexity. In this sense, the postdigital reminds us of the complex effects and affects which are at work as a result of the shift in our experience of technology; it acts as a call to continually attempt to think the impact of the digital, and to note that it is perhaps at the very moment of its forgetting or absence - in the infiltration of algorithmic control mechanisms into our daily lives, for example - that the force of that impact is at its strongest.

\section{Open Review 1: Dialogic responses, dynamics and provocations (Christine)}

This interplay among the voices simultaneously keeps them separate and holds them together, that is, constitutes them as a social body. (Evans 2008: 75)

Our collective paper brings to mind Evans' (2008) construct of the 'multivoiced body', which encompasses the global public and the microcosms within it. Through dialogic interaction, the multivoiced body has the potential to resist the rise of universalising doctrines - claiming the one right way - which Evans calls 'oracles'. It is useful to explore here how the collective is constituted through authors' individual responses to the original editorial by Jandrić, Knox et al (2018), as well as the dialogic dynamics across their separate contributions, and their provocations to further dialogue. While the paper contains a sense that 'something needs to be done', there is no recourse to oracles.

My own response inevitably adds to the dynamics, perhaps especially in relation to the contention that the first postdigital dialogue has failed. I maintain that it hasn't finished yet, so we can't say that. Indeed, a dialogue may never conclude; here dialogue differs from dialectic (Wegerif, 2017), which is not to deny that it can be progressive. Most of the interlocutors here, including some of the original authors, are responding to the editorial in Educational Philosophy and Theory ${ }^{3}$. Some have a follow-up role and are responding to the paper in progress, for example by editing and sequencing it, or by introducing, concluding or reviewing. All of the follow-up interlocutors, including myself, express the hope that the dialogue will continue. How, then, might we be spared

\footnotetext{
${ }^{3}$ https://www.tandfonline.com/loi/rept20.
} 
from 'circling the drain' with the dialogue's blabbering? The paper itself contains some suggestions: both theoretical and practical.

Despite the original editorial's attempt to pin down the postdigital, one response has been that the word needs to be qualified in some way; suggestions include a preceding adjective and a subsequent noun. Indeed, critical postdigital reflexivity may well be a shared aspiration, combining a broad theoretical orientation with the acknowledgement that we will be doing something in the postdigital context that will affect how we think and talk about it. The sequencing of the paper admirably moves from understanding the construct, identifying hopes and warnings, and culminating in fascinating accounts of situations where the postdigital is in evidence.

However, qualifying the postdigital has some further complexity. Its point of reference - the digital - may be unseen or absent. The conclusion warns that the digital may even be exorcised by certain forms of authority, echoing Evans' (2008) concerns about oracles. Capitalism, globalisation, neoliberalism, and commercialization all appear in the paper as potential candidates for oracles governing the digital or the postdigital, particularly when exacerbated by algorithmic control. It is understandable that resistance to such forces is sometimes accompanied by exhortations: what we must, need and ought to do. This is important; while the digital starts to become invisible, the paper points out that citizens, especially students, are rendered visible through digital surveillance and normalization. We need this awareness, we need urgently to discuss the associated obligations of science and education, and we need the dynamism of many voices in that dialogue.

A dialogue seems an excellent way to begin a new journal. There should at least be as many readers as authors, and there will probably be many more. And the provocations here are worthy of response.

\section{Open Review 2: Entangled academic subjectivity (Michael)}

In the common understanding, peer review is a process in which the name of the reviewer is not disclosed to the authors. In Educational Philosophy and Theory I tried to experiment with the form in relation to collective writing projects so that reviewing became a collective process where the reviewer could add something more to the text, even 'become part of the text' while at the same time passing a judgment on the work of the text that has been assembled and developed by a group or network of authors. It's a complex and self-reflective evaluation that differs from traditional peer review. This paper is an example of the collective subject and the mode of collective intelligence that collaboration and especially collective writing can produce. And for this reason, it contains many different perspectives like refracted light that actually casts light on the theme which is academically interesting. In a condensed form that departs from the old industrial capitalist genre of the standard article, this kind of article-assemblage demands focus. Open peer review seems a good method to assess the outcome because in fact often as in this case it is based on a 'community of scholars' and represents several strands of research and writings that form a complex writing system.

In this case I need to acknowledge my own embeddedness - not in the production of this paper - but with various of the author-scholars in previous collaborative writing projects. I am inscribed in all sorts of ways. The questions of fair assessment and review is therefore impossible without indicating my own biases which is towards collective work, experimentation and the participation of multiple authors. Epistemologically I think this form has advantages - a kind of pluralism that helps to resist ideology and 'nepotism'. I also have a bias toward complexity, brevity, condensation. This is why I like this paper: its form pleases me. Its political praxis explores many possible meanings of the 'post' and experiments with new approaches including the critique of the digital, or its 
pervasiveness - its ubiquity - that now has become a part of us and that conditions the new mode of being or ways of existing. Everything is defined by the digital. The postdigital is not confined to critique of culture, knowledge, media, logic, system but includes aesthetics and the politics of design. Through 'author-review' I am already a part of this paper by 19 authors and indebted to the original paper (Jandrić, Knox at al. 2018) which was written by six authors.

I am caught in the net of 'postdigitalism' - 'after, with, and against', and the digital as a critical attitude which recognises the rupture and continuation. The implicit entanglements are thematically repeated by many of the authors: digital and bio; digital and physical; virtual and textual; and 'automediated' postdigital user-generated media. These Derridean entanglements also involve identities, practices, forms of self-representation, including the postdigital as a form of 'community of praxis.' The critical element for me is the Kantian 'critique of digital reason' as an examination of possible conditions of postdigital forms of logic and knowledge. The scholars in this paper develop the concept of the 'postdigital' as the agenda of both the critical humanities and critical pedagogy. The 'postdigital' is what it means to be human in the time of digital capitalism considered as an ontological and cultural horizon. This emerges and serves as a focus for postcritical activity, 'the humanization of digital technologies,' but also a better understanding of $5^{\text {th }}$ generation cybernetic rationality, the cause of trade wars around the roll out of $5 \mathrm{G}$ networks, and a radical political economy that can effectively analyse interlocking systems of the trillion-dollar global digital giants. My recommendation is to publish. Let's see what comment it provokes.

\section{References}

Adams, T. Facebook's week of shame: the Cambridge Analytica fallout. The Guardian. Available: https://www.theguardian.com/technology/2018/mar/24/facebook-week-of-shame-databreach-observer-revelations-zuckerberg-silence

Ahlquist, J. (2015). Developing digital student leaders: A mixed methods study of student leadership, identity and decision making on social media. (Doctoral dissertation, California Lutheran University) ProQuest, LLC. UMI Number: 3713711.

Amsler, S. (2015). The Education of Radical Democracy. London: Routledge.

Andersen, C. U., Cox, G., \& Papadopoulos, G. (2014). Postdigital research-editorial. A PeerReviewed Journal About, 3(1).

Asher, G. (2015). Working In, Against and Beyond the Neoliberal University. Presentation for SCUTREA conference. https://www.academia.edu/13925922/Working_in_against_and_beyond_the neoliberal_uni versity. Accessed 25 January 2019.

Asher, G. (2017). The Porous University: Opening up the University; Being and becoming critically academically literate? Presentation for The Porous University Symposium: The Porous University - A critical exploration of openness, space and place in Higher Education, May, 2017, University of the Highlands and Islands. https://www.raggeduniversity.co.uk/2017/06/05/the-porous-university-opening-up-theuniversity-being-and-becoming-critically-academically-literate-by-gordon-asher/. Accessed 25 January 2019.

Asher, G. (2018). Critical Dialogues for Learning and Technology: In, against and beyond the neoliberal university. Open Review of Educational Research, 5(1), 144 -149. https://doi.org/10.1080/23265507.2018.1547950 
Australian Curriculum, Assessment Reporting Authority. (n.d.) Information and Communication Technology (ICT) Capability. https://www.australiancurriculum.edu.au/f-10curriculum/general-capabilities/information-and-communication-technology-ict-capability/. Accessed 25 January 2019.

Bacevic, J. (2017). Why is it more difficult to imagine the end of universities than the end of capitalism, or: is the crisis of the university in fact a crisis of imagination? Jana Bacevic: Internal conversation, eternal emigration, 17.10.2017., https://janabacevic.net/2017/10/11/is -the -crisis -of -the - university -in -fact - a -crisis - of -imagination/. Accessed 25 January 2019.

Bauman, Z. (2008). Los retos de la educación en la modernidad líquida. Barcelona: Gedisa.

Berg, M. \& Seeber, B. K. (2016). The Slow Professor. University of Toronto Press.

Berry, D. M., \& Fagerjord, A. (2017). Digital humanities: Knowledge and critique in a digital age. Cambridge, England; Malden, MA: Polity Press.

Bogner, A., \& Menz, W. (2009). The theory-generating expert interview: Epistemological interest, forms of knowledge, interaction. In A. Bogner, B. Littig, \& W. Menz (Eds.), Interviewing experts (pp. 43-80). Basingstoke, UK: Palgrave Macmillan.

Bookchin, M. (1990). The Meaning of Confederalism. Green Perspectives, 20. http://dwardmac.pitzer.edu/anarchist_archives/bookchin/gp/perspectives20.html. Accessed 25 January 2019.

Boyd, D. M. \& Ellison, N. B. (2008). Social network sites: Definition, history and scholarship. Journal of Computer-Mediated Communication, 13, 210-230. https://doi.org/10.1111/j.10836101.2007.00393.x

Buchanan, R. (2011). Paradox, Promise and Public Pedagogy: Implications of the Federal Government's Digital Education Revolution. Australian Journal of Teacher Education, 36(2). https://doi.org/10.14221/ajte.2011v36n2.6

Canaan, J. (2012). Critical pedagogy, in, against and beyond the neoliberalised university. ESRC seminar Global Citizenship as a Graduate Attribute, UCL, 14 October 2011. http://andreasbieler.net/wp -content/files/Canaan\%20Critical\%20pedagogy.pdf. Accessed 25 January 2019.

Cantwell, B. \& Kauppinen, I. (Eds.) (2014). Academic Capitalism in the Age of Globalisation. Baltimore, MA: John Hopkins University Press.

Carrion, V. G., Weems, C. F., \& Reiss, A. L. (2007). Stress predicts brain changes in children: A pilot longitudinal study on youth stress, posttraumatic stress disorder, and the hippocampus. Pediatrics, 119(3), 509-516. 10.1542/peds.2006-2028

Chomsky, N. (2017). Preface. In M. Albert, Practical Utopia: Strategies for a Desirable Society. Edinburgh: PM Press.

Clarke, M., \& Moore, A. (2013). Professional standards, teacher identities and an ethics of singularity. Cambridge Journal of Education, 43(4), 487-500. https://doi.org/10.1080/0305764X.2013.819070

Cope, B., \& Kalantzis, M. (Eds.). (2000). Multiliteracies: Literacy learning and the design of social futures. London: Routledge.

Cowden, S. \& Singh, G. (2013). Acts of Knowing: Critical Pedagogy in, Against and Beyond the University. London: Bloomsbury.

Crone, E. A., \& Konijn, E. A. (2018). Media use and brain development during adolescence. Nature Communications, 9(1). 10.1038/s41467-018-03126-x 
Crowther, J., Galloway, V., \& Martin, I. (2005). Popular Education: Engaging the Academy International Perspectives. Leicester: NIACE.

Darder, A. (2015). Freire and Education. London: Routledge.

Davie, G. (1990). The Democratic Intellect. Edinburgh: Edinburgh University Press.

Dean, J. (2017). Doing reflexivity: An introduction. Policy Press.

Delors, J. (1996). La educación encierra un tesoro. Santillana: Ediciones Unesco.

Deng, R., Benckendorff, P., \& Gannaway, D. (2019). Progress and new directions for teaching and learning in MOOCs. Computers and Education, 129, 48-60. https://doi.org/10.1016/j.compedu.2018.10.019

Department of Education and Training. (2018). Through growth to achievement: The report of the review to achieve educational excellence in Australian schools (p. 158). Canberra, ACT: Commonwealth of

Australia. https://docs.education.gov.au/system/files/doc/other/662684_tgta_accessible_final_0.pdf. Accessed 25 January 2019.

Derrida, J. (1990). Let us not Forget - Psychoanalysis. Oxford Lit Review, 12(1), 3-8. 10.3366/olr.1990.001

D’Olimpio, L. (2018). Media and Moral Education: A philosophy of critical engagement. London: Routledge.

Edwards, R., \& Usher, R. (2008). Globalisation and pedagogy: Space, place, and identity (2nd ed.). London: Routledge.

Edwards, S. (2013). Digital play in the early years: a contextual response to the problem of integrating technologies and play-based pedagogies in the early childhood curriculum. European Early Childhood Education Research Journal, 21(2), 199-212. https://doi.org/10.1080/1350293X.2013.789190

Escaño, C. (2013). Educación move commons. Procomún, cultura Libre y acción colaborativa desde una pedagogía crítica, mediática y e-visual. Arte, Individuo y Sociedad, 25(2), 319-336. https://doi.org/10.5209/rev_ARIS.2013.v25.n2.39078

Evans, F. (2008). The Multivoiced Body. Columbia: Columbia University Press.

Falcone T. (2013). Biomarkers for depression and schizophrenia: A progress update. Paper presented at 11th World Congress of Biological Psychiatry; June 2013; Kyoto, Japan.

Fawns, T. (2018). Postdigital Education in Design and Practice. Postdigital Science and Education. https://doi.org/10.1007/s42438-018-0021-8

Feenberg, A. (2019). Postdigital or predigital? Postdigital Science and Education. https://doi.org/10.1007/s42438-018-0027-2

Ford, D. R. (2016). Communist study: Education for the commons. Lanham: Lexington Books.

Ford, D. R. (2017). Studying Like a Communist: Affect, the Party, and the Educational Limits to Capitalism. Educational Philosophy and Theory, 49(5), 452-461. https://doi.org/10.1080/00131857.2016.1237347

Ford, D.R. (2019). Politics and pedagogy in the "post-truth" era: Insurgent philosophy and praxis. London: Bloomsbury.

Freire, P. (2005). Pedagogy of the Oppressed. New York: Continuum.

Fuller, S. \& Jandrić, P. (2018). The Postdigital Human: Making the History of the Future. Postdigital Science and Education. https://doi.org/10.1007/s42438-018-0003-X 
Gee, J. P. (2009). Reflections on Reading Cope and Kalantzis' “'Multiliteracies': New Literacies, New Learning”. Pedagogies: An international journal, 4(3): 196-204. https://doi.org/10.1080/15544800903076077

Gibson, W. (2010). Zero History. New York: Berkley Books.

Giroux, H. (2011). On Critical Pedagogy. London: Continuum.

Giroux, H. (2014). Neoliberalism's War on Higher Education. Chicago: Haymarket Books.

Giroux, H. (2017). Rethinking Higher Education in a Time of Tyranny. Truthdig, 14 October. https://www.truthdig.com/articles/rethinking -higher-education -time-tyranny/. Accessed 25 January 2019.

Grebowicz, M. (2017). Whale Song. London: Bloomsbury.

Haiven, M. (2014). Capitalism's crisis of value and imagination. Truthout, 8 February. https://truthout.org/articles/capitalisms -crisis - of -value -and -imagination/. Accessed 25 January 2019.

Hall, R. (2018) The Alienated Academic: The Struggle for Autonomy Inside the University. London: Palgrave McMillan.

Hartanto, A. \& Yang, H. (2016). Is the smartphone a smart choice? The effect of smartphone separation on executive functions. Computers in Human Behavior, 64, 329-336. https://doi.org/10.1016/j.chb.2016.07.002

Hayes, S. (2019). The Labour of Words in Higher Education. Rotterdam: Brill Sense.

Hika Group (2018). Hika Explorer. http://hikagroup.com/Hika-App/. Accessed 25 January 2019.

Holloway, J. (2016). In, Against and Beyond Capitalism: The San Francisco Lectures. Oakland, CA: PM Press.

Horton, M. \& Freire, P. (1990). We Make the Road by Walking: Conversations on Education and Social Change. Philadelphia: Temple University Press.

Hoskins, T. K., \& Jones, A. (Eds.). (2017). Critical conversations in Kaupapa Māori. Wellington, NZ: Huia Publishers.

Jandrić, P. \& Boras, D. (Eds.). (2015). Critical Learning in Digital Networks. New York: Springer.

Jandrić, P., Knox, J., Besley, T., Ryberg, T., Suoranta, J., \& Hayes, S. (2018). Postdigital science and education. Educational Philosophy and Theory, 50(10), 893-899. https://doi.org/10.1080/00131857.2018.1454000

Jandrić, P., Ryberg, T., Knox, J., Lacković, N., Hayes, S., Suoranta, J., et al. (2018). Postdigital Dialogue. Postdigital Science and Education. https://doi.org/10.1007/s42438-018-0011-X

Jandrić, P. (2017). Learning in the Age of Digital Reason. Rotterdam: Sense.

Jandrić, P. (2018). Welcome to Postdigital Science and Education! Postdigital Science and Education. https://doi.org/https://doi.org/10.1007/s42438-018-0013-8

Jenkins, H. (2008). Convergence Culture. La cultura de la convergencia de los medios de comunicación. Barcelona: Paidos.

Jones, S. R., \& Abes, E. S. (2013). Identity development of college students: Advancing frameworks for multiple dimensions of identity. Chichester: Wiley.

Jouët, J. (2018). Digital feminism: Questioning the renewal of activism. Journal of Research in Gender Studies, 8, 133-157. 10.22381/JRGS8120187

Kaplún, M. (1998). Una pedagogía de la comunicación. Madrid; Ediciones de la Torre.

King, A. L.; Valença, A. M.; Silva, A. C.; Sancassiani, F.; Machado, S.; Nardi, A. E. (2014). 'Nomophobia': Impact of cellphone use interfering with symptoms and emotions of 
individuals with panic disorder compared with a control group. Clinical Practice and Epidemiology in Mental Health, 10, 28 - 35. 10.2174/1745017901410010028

Kirschner, P. A., \& De Bruyckere, P. (2017). The myths of the digital native and the multitasker. Teaching and Teacher Education, 67, 135-142. https://doi.org/10.1016/j.tate.2017.06.001

Kumashiro, K. (2015). Against common sense: Teaching and learning toward social justice. New York, NY: Routledge.

Lupton, D., \& Williamson, B. (2017). The datafied child: The dataveillance of children and implications for their rights. New Media \& Society, 19(5), 780-794. https://doi.org/10.1177/1461444816686328

Maguire, E. (2018). Girls, autobiography, media: Gender and self-mediation in digital economies. Cham: Palgrave Macmillan.

Mallan, K. (2009). Look at me! Look at me! Self-representation and self-exposure through online networks. Digital Culture and Education, 1(1), 51-66.

May, S. (2012). Language \& minority rights: ethnicity, nationalism and the politics of language (2nd ed.). New York: Routledge.

McFarland, A., \& Matthews, N. (Eds.). (2017). He kete whakawaitara: he whakatara ā-rangahau. Wellington, NZ: NZCER Press.

McLaren, P., \& Jandrić, P. (2014). Critical revolutionary pedagogy is made by walking: In a world where many worlds coexist. Policy Futures in Education, 12(6), 805-831. https://doi.org/10.2304/pfie.2014.12.6.805

Mendoza, J. S.; Pody, B. C.; Lee, S; Kim, M.; \& McDonough, I. M. (2018). The effect of cellphones on attention and learning: The influences of time, distraction, and nomophobia. Computers in Human Behavior, 86, 52-60. https://doi.org/10.1016/j.chb.2018.04.027

Mihăilă, R., \& Mateescu, M. (2017). The gender politics of postfeminist semantics. Journal of Research in Gender Studies, 7, 255-261. 10.22381/JRGS71201710

Mills, C. W. (1940). Methodological consequences of the sociology of knowledge. American Journal of Sociology, 46(3), 316-330.

Mills, C. W. (1959). Sociological Imagination. New York: Oxford University Press.

Mirică (Dumitrescu), C.-O. (2018). Online contingent labor in a precarious capitalism: Platform business models, nonstandard forms of employment, and digitally driven sharing-economy services. Journal of Self-Governance and Management Economics, 6, 129-135. 10.22381/JSME6320184

Mitea, D. R. E. (2018). The expansion of digitally mediated labor: Platform-based economy, technology-driven shifts in employment, and the novel modes of service work. Journal of Self-Governance and Management Economics, 6, 7-13. 10.22381/JSME6420181

Morris, S. M. \& Stommel, J. (2018a). An Urgency of Teachers. Hybrid Pedagogy, 11 September. http://hybridpedagogy.org/an -urgency -of-teachers/. Accessed 25 January 2019.

Morris, S. M. \& Stommel, J. (2018b). An Urgency of Teachers: The Work of Critical Digital Pedagogy. Hybrid Pedagogy Inc.

Morrish, L. (2018). Can Critical University Studies Survive the Toxic University? Academic Irregularities, 11. June. https://academicirregularities.wordpress.com/2018/06/08/cancritical-university-studies-survive-the-toxic-university/. Accessed 25 January 2019.

Negroponte, N. (1998). Beyond digital. Wired, 12 January. http://www.wired.com/wired/archive/6.12/negroponte.html. Accessed 25 January 2019. 
New Zealand Digital Library. (2018). Niupepa - Mäori Newspapers. www.nzdl.org/niupepa. Accessed 25 January 2019.

New Zealand Legislation. (1987). Māori Language Act. http://www.legislation.govt.nz/act/public/1987/0176/latest/DLM124116.html. Accessed 25 January 2019.

Olsen-Reeder, V. I., Hutchings, J., \& Higgins, R. (Eds.). (2017). Te ahu o te reo Māori: reflecting on research to understand the well-being of te reo Māori. Wellington, NZ: Victoria University Press.

Osuna Acedo, S., Frau-Meigs, D., Camarero Cano, L., Bossu, A., Pedrosa, R., \& Jansen, D. (2017). Intercreativity and interculturality in the virtual learning environments of the ECO MOOC project. In M. Jemni, Kinshuk, \& M. K. Khribi (Eds.), Open Education: from OERs to MOOCs (pp. 161-187). Springer. https://doi.org/10.1007/978-3-662-52925-6

O'Neil, C. (2017). Weapons of Math Destruction: How Big Data Increases Inequality and Threatens Democracy. London: Penguin.

Peters, M. \& Jandrić, P. (2018). The Digital University: A Dialogue and Manifesto. New York: Peter Lang.

Peters, M. A., \& Besley, T. (2018). Critical Philosophy of the Postdigital. Postdigital Science and Education. https://doi.org/10.1007/s42438-018-0004-9

Peters, M. A., Rider, S., Hyvönen, M., \& Besley, T. (2018). Post-Truth, Fake News. Viral Modernity \& Higher Education. Springer. https://doi.org/10.1007/978-981-10-8013-5

Peters, M. A. (2012). Bio-informational capitalism. Thesis Eleven, 110(1), 98-111. https://doi.org/10.1177/0725513612444562

Peters, M. A., Besley, A. C. T., \& Arndt, S. (2019). Experimenting with academic subjectivity: collective writing, peer production and collective intelligence. Open Review of Educational Research, 6(1), 25-39. https://doi.org/10.1080/23265507.2018.1557072

Roberts, P. (1996). Rethinking Conscientisation. Journal of Philosophy of Education, 30(2), 179-196. https://doi.org/10.1111/j.1467-9752.1996.tb00390.x

Roca-Sales, M., \& Lopez-Garcia, G. (2017). Contemporary portrayals of women and femininity. A case study of lifestyle blogs in the U.S. Journal of Research in Gender Studies, 7, 186-210. 10.22381/JRGS72201710

Ryberg, T., Davidsen, J., \& Hodgson, V. (2018). Understanding nomadic collaborative learning groups: Nomadic collaborative learning groups. British Journal of Educational Technology, 49(2), 235-247. https://doi.org/10.1111/bjet.12584

Shalom, S. (2008). A Political System for a Good Society. ZNet, 31. December. https://zcomm.org/znetarticle/a-political-system-for-a-good-society-by-stephen1-shalom. Accessed 25 January 2019.

Sheppard, E. (2018). 10 Best Planners for 2019: be more organised this year by keeping a bullet journal or planner. https://www.independent.co.uk/extras/indybest/books/stationery/best2019-planners-a8022781.html. Accessed 25 January 2019.

Sinclair, C. \& Hayes, S. (2018). Between the Post and the Com-Post: Examining the Postdigital 'Work' of a Prefix. Postdigital Science and Education, 1(1). https://doi.org/10.1007/s42438018-0017-4.

Smithies, J. (2017). The digital humanities and the digital modern. London: Palgrave Macmillan.

Sorell, T. (1991). Scientism: Philosophy and the infatuation with science. London and New York: Routledge. 
Stewart, G., \& Dale, H. (2018). Reading the 'ghost book': Māori talk about Washday at the Pā, by Ans Westra. Video Journal of Education and Pedagogy, 3(2). 10.1186/s40990-018-0014-2

Stewart, G., Tamatea, K., \& Mika, C. (2015). Infinitely welcome: education pōwhiri and ethnic performativity. MAI Journal, 4(2), 91-103.

Stewart, G. (2017). Kaupapa Māori theory as a philosophy for education. In T. K. Hoskins \& A. Jones (Eds.), Critical conversations in Kaupapa Mãori (pp. 133-146). Wellington: Huia Publishers.

Sullivan, C. (2018). Digital identity - From emergent legal concept to new reality. Computer Law \& Security Review, 34(4), 723-731. 10.1016/j.clsr.2018.05.015

Sundén, J. (2003). Material Virtualities. New York: Peter Lang.

Suoranta, J. (2010). Learners and Oppressed Peoples of the World, Wikify! In C. Malott \& B. Porfilio (Eds.), Critical Pedagogy in the 21st Century: A New Generation of Scholars. Charlotte, North Carolina: Information Age Publishing.

Suoranta, J. \& Renfors, A. (forthcoming 2019). Learning Democracy by Doing Wikiversity. In P. Carr, M. Hoechsmann, \& G. Thésée, G. (Eds.), Democracy 2.0: Media, Political Literacy and Education in the Era of Corporate and (Potentially) Participatory Media. Rotterdam: Sense Publishers.

Suoranta, J. \& Vadén, T. (2012). Wikilearning as Radical Equality. In P. Trifonas (Ed.), Learning in the Virtual: Public Pedagogy in the Digital Age. London \& New York: Routledge.

Taffel, S. (2016). 'Perspectives on the postdigital: beyond rhetorics of progress and novelty', Convergence: The International Journal of Research into New Media Technologies, 22(3), 324-338. https://doi.org/10.1177/1354856514567827

Torres, V., Jones, S. R., \& Renn, K. A. (2009). Identity development, theories in student affairs origins, current status, and new approaches. Journal of College Student Development, 50(6), 577-596. 10.1353/csd.0.0102

Toyokawa, S., Uddin, M., Koenen, K. C., \& Galea, S. (2012). How does the social environment "get into the mind"? Epigenetics at the intersection of social and psychiatric epidemiology. Social Science \& Medicine, 74(1), 67-74. 10.1016/j.socscimed.2011.09.036

Wakefield, A., Cartney, P., Christie, J., Smyth, R., Cooke, A., Jones, T., ... Kennedy, J. (2018). Do MOOCs encourage corporate social responsibility or are they simply a marketing opportunity? Nurse Education in Practice, 33, 37-41. https://doi.org/10.1016/j.nepr.2018.08.020

Wegerif, R. (2017). Dialogic and dialectic: clarifying an important distinction. http://www.rupertwegerif.name/blog/dialogic-and-dialectic-clarifying-an-importantdistinction. Accessed 16 February 2019.

Williams, J. J. (2012). Deconstructing Academe: The Birth of Critical University Studies. Chronicle of Higher Education, 19 February. https://www.chronicle.com/article/An-Emerging-FieldDeconstructs/130791. Accessed 25 January 2019.

Wittgenstein, L. (1958). Philosophical Investigations. 2 ed. Oxford: Blackwell.

Wordstream. (2018). Wakareo. http://www.reotupu.co.nz/wslivewakareo/. Accessed 25 January 2019.

Yildirim, C., \& Correia, A. (2015). Exploring the dimensions of nomophobia: Development and validation of a self-reported questionnaire. Computers in Human Behavior, 49, 130-137. https://doi.org/10.1016/j.chb.2015.02.059 
Zhao, S., Grasmuck, S., \& Martin, J. (2008). Identity construction on Facebook: Digital empowerment in anchored relationships. Computers in Human Behavior, 24, 1816-1836. https://doi.org/10.1016/j.chb.2008.02.012 